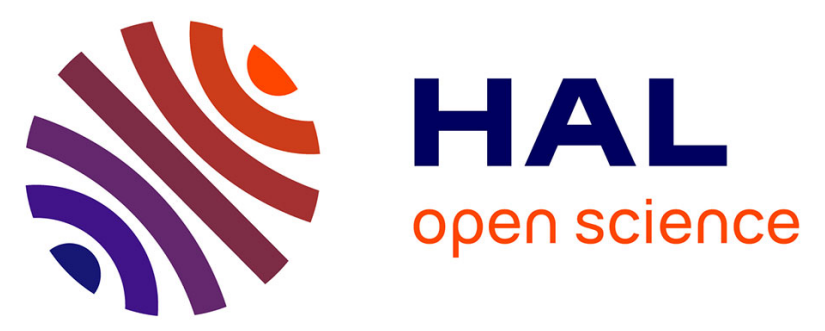

\title{
A new acoustic resonator concept based on acoustic waveguides using Silicon/Periodically Poled Transducer/Silicon structures for RF applications
}

F. Bassignot, G. Ulliac, J.-M. Lesage, J. Garcia, E. Courjon, B. François, S. Ballandras

\section{To cite this version:}

F. Bassignot, G. Ulliac, J.-M. Lesage, J. Garcia, E. Courjon, et al.. A new acoustic resonator concept based on acoustic waveguides using Silicon/Periodically Poled Transducer/Silicon structures for RF applications. 5th Joint Conference of the 65th IEEE International Frequency Control Symposium/25th European Frequency and Time Forum, May 2011, San Francisco, United States. pp.363368, 10.1109/FCS.2011.5977823 . hal-00651266

\section{HAL Id: hal-00651266 https://hal.science/hal-00651266}

Submitted on 9 Apr 2021

HAL is a multi-disciplinary open access archive for the deposit and dissemination of scientific research documents, whether they are published or not. The documents may come from teaching and research institutions in France or abroad, or from public or private research centers.
L'archive ouverte pluridisciplinaire HAL, est destinée au dépôt et à la diffusion de documents scientifiques de niveau recherche, publiés ou non, émanant des établissements d'enseignement et de recherche français ou étrangers, des laboratoires publics ou privés. 


\title{
A new acoustic resonator concept based on acoustic waveguides using Silicon/Periodically Poled Transducer/Silicon structures for RF applications
}

\author{
Florent Bassignot, Gwenn Ulliac, Jean-Marc Lesage*, Julien Garcia, Emilie Courjon, \\ Bruno François, Sylvain Ballandras \\ Institut FEMTO-ST, Besançon, France \\ *CELAR, DGA, Rennes, France \\ Email: florent.bassignot@femto-st.fr
}

Abstract: We propose a new acoustic resonator concept based on a periodically poled transducer (PPT) in a piezoelectric substrate $\left(\mathrm{LiNbO}_{3}\right.$ or $\left.\mathrm{LiTaO}_{3}\right)$, embedded between two guiding substrates in order to create an acoustic waveguide. A resonator operating at $131 \mathrm{MHz}$ have been successfully fabricated and used in order to stabilize an oscillator. However the fabricated resonator presents a significant thermal sensitivity. The following experiments have consisted in studying a Si/thinned PPT layer/Si in order to reduce the thermal sensitivity.

\section{INTRODUCTION}

Surface Acoustic Waves resonators are usually used for the frequency stabilization of electrical oscillators in the range of $50 \mathrm{MHz}$ to $2 \mathrm{GHz}$. We have developed an isolated wave guide allowing for the propagation of acoustic waves within a PPT plate $\left(\mathrm{LiNbO}_{3}\right.$ or $\left.\mathrm{LiTaO}_{3}\right)$ in between two silicon guiding substrates, yielding advanced packaging opportunities. In the first part, we present the simulation, the fabrication and the characterization of a PPT-based resonator operating at $131 \mathrm{MHz}$ with a Silicon $(380 \mu \mathrm{m}) / \mathrm{LiNbO}_{3} \mathrm{PPT}(500 \mu \mathrm{m}) / \operatorname{Silicon}(380 \mu \mathrm{m})$ structure. We present the resonator oscillation characteristics, more particularly the phase noise and the frequency stability. In a second part, we exhibit the advantages of thinning down the piezoelectric transducer in showing the dispersion properties analysis. We describe the fabrication process and the characterization of resonators based on thinned PPLN or PPLT layers. The phase noise of an oscillator using a Si/PPLN/Si resonator, exhibiting a 50 $\mu \mathrm{m}$ period and a 500 $\mu \mathrm{m}$ thick piezoelectric layer, has pointed out the concept feasibility and answers to scope statement. In fact, these resonators, with low insertion losses and a phase noise at $100 \mathrm{kHz}$ of the carrier wave controlled, less than $160 \mathrm{dBc} / \mathrm{Hz}$, are well-suited for radar applications. Moreover, for each PPT period, the dispersion properties analysis has shown an optimum thickness of the piezoelectric plate, corresponding to the maximum electromechanical coupling coefficient. Si/PPT/Si test vehicles, exhibiting a 50 $\mu$ m period and a thick piezoelectric layer around $30 \mu \mathrm{m}$, have pointed out the existence of an isolated mode operating at frequencies near $110 \mathrm{MHz}$ for a $\mathrm{LiNbO}_{3}$ PPT and near $90 \mathrm{MHz}$ with $\mathrm{LiTaO}_{3} \mathrm{PPT}$ with low thermal sensitivities.

\section{BASIC PRINCIPLES OF THE PPT-BASED RESONATOR}

We propose a new guiding concept using interface ultrasonic waves. We suggest a compact structure based on poled ferroelectric layer bonded between two guiding substrates (fig.1). An acoustic wave is excited by a periodically poled transducer, and the waves then are trapped within a buried guiding structure. $\mathrm{LiNbO}_{3}$ or $\mathrm{LiTaO}_{3}$ as piezoelectric and ferroelectric materials are exploited to fabricate the PPT's [1] and silicon substrates are used to guide the acoustic wave and allow for a low cost packaging [2]. These components have to operate at high frequencies (RF until X band domain) and need spectral purity, short-term stability, low phase noise around the carrier wave and thermal insensitivity notably for radar applications. PPTs have been investigated recently as an alternative to standard periodic inter-digital 
transducers (IDTs) for the excitation and detection of guided acoustic waves [2] and consist of a periodic alternation of oppositely poled ferroelectric domains included between two electrodes. The main advantages of PPTs compared to standard IDTs are the robustness of the excitation versus defects or surface contamination, the opportunity to excite fundamental waves exhibiting an operating frequency twice higher and the possibility to excite several waves at the same time.

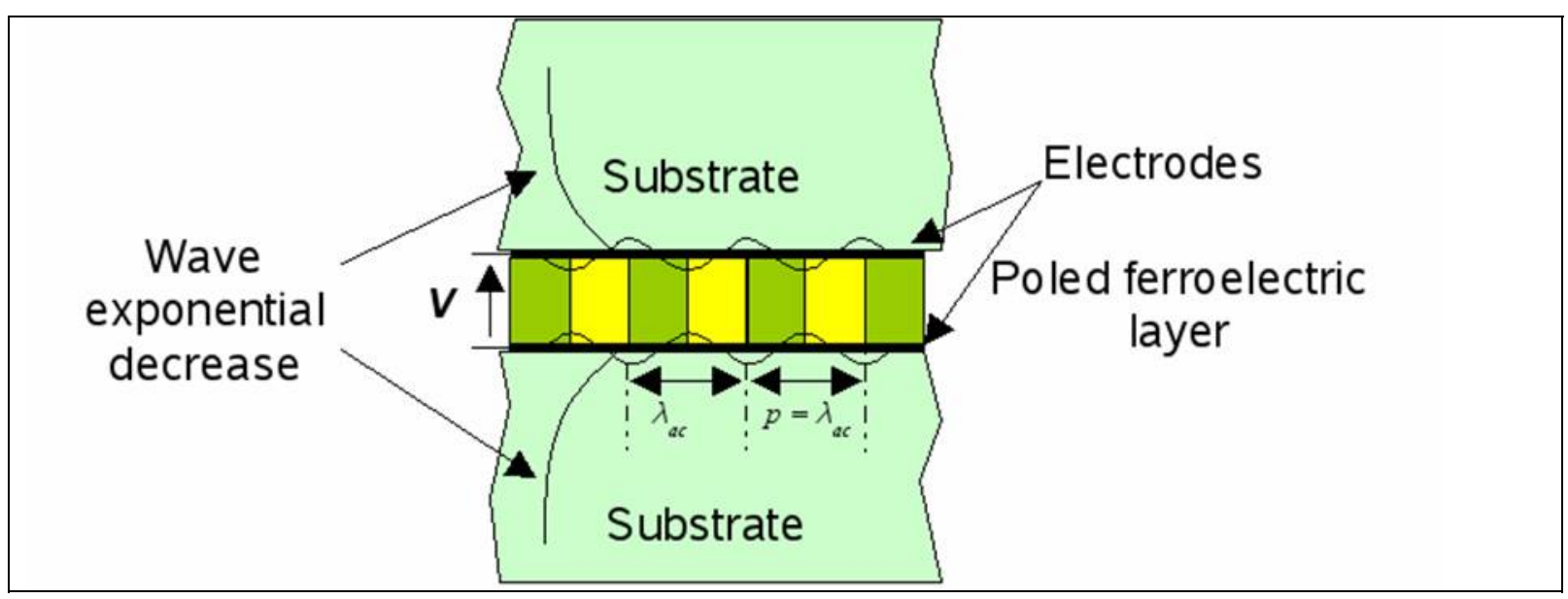

Fig. 1. Principle of the PPT isolated wave transducer

\section{Si/thick PPT/Si- BASED WAVEGUIDE, RESONATOR AND OSCILLATOR}

The fabrication of acoustic waveguides based on PPTs consists in bonding a silicon wafer on each side of the periodically poled wafer. $\mathrm{LiNbO}_{3}$ or $\mathrm{LiTaO}_{3}$ as piezoelectric and ferroelectric materials are good candidates for the fabrication of the PPTs. In fact, these materials have a spontaneous polarization which can be inverted by applying high voltage thanks to our homemade poling technique [3]. The voltage needed to invert the domains is around $11 \mathrm{kV}$ for a $500 \mu \mathrm{m}$-thick wafer. The different steps of fabrication are detailed in fig. 2 and reported in reference [4].

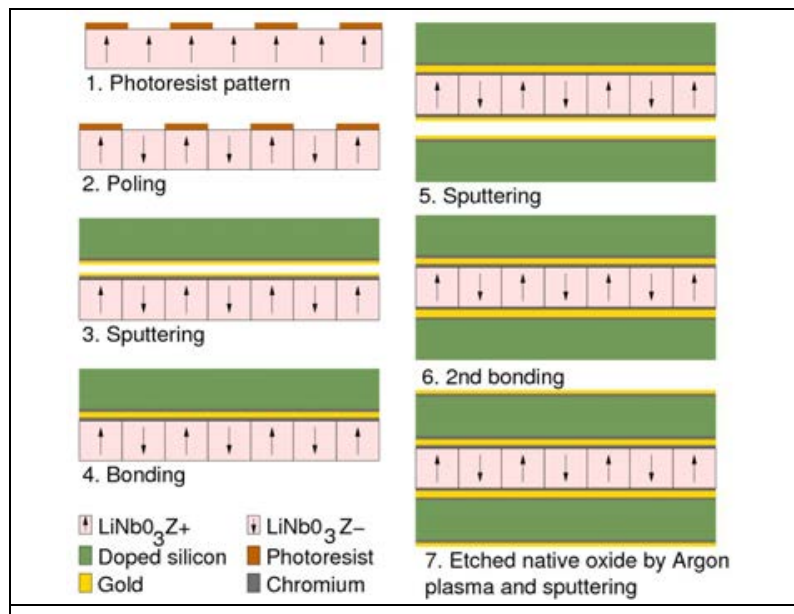

Fig.2. Flow-chart of fabrication

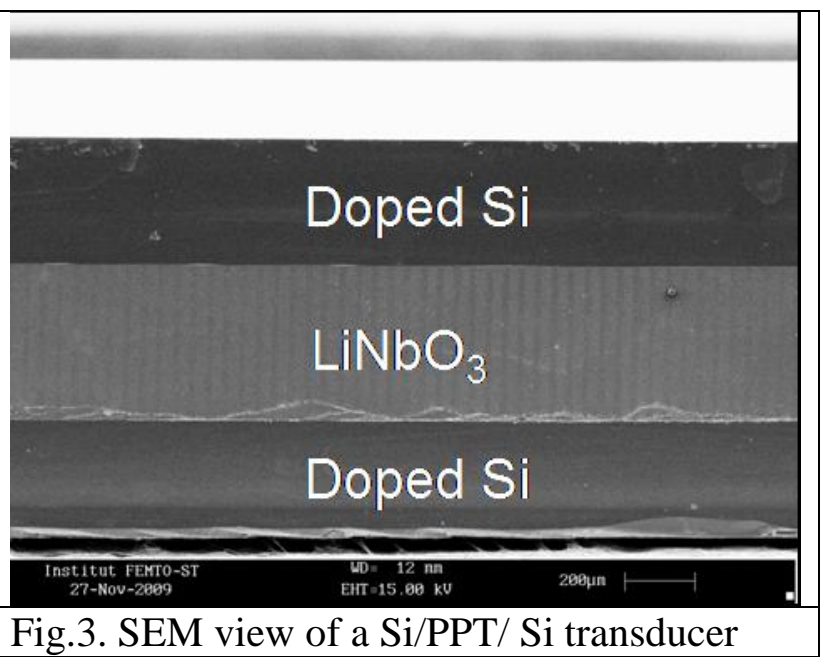

Fig.3. SEM view of a Si/PPT/ Si transducer

On figure 3, we can see a SEM observation of poled domains after HF wet etching for a $50 \mu \mathrm{m}$ period of this Si/500 $\mu \mathrm{m}$ PPT/Si structure. The different domains confined between the 2 doped silicon layers are clearly observed. Operational test vehicles with a 50 $\mathrm{mm}$ period have been achieved using doped silicon wafers in order to ease the electrical contact and tested by means of a spectrum analyzer yielding Si/PPT/Si devices responses. 


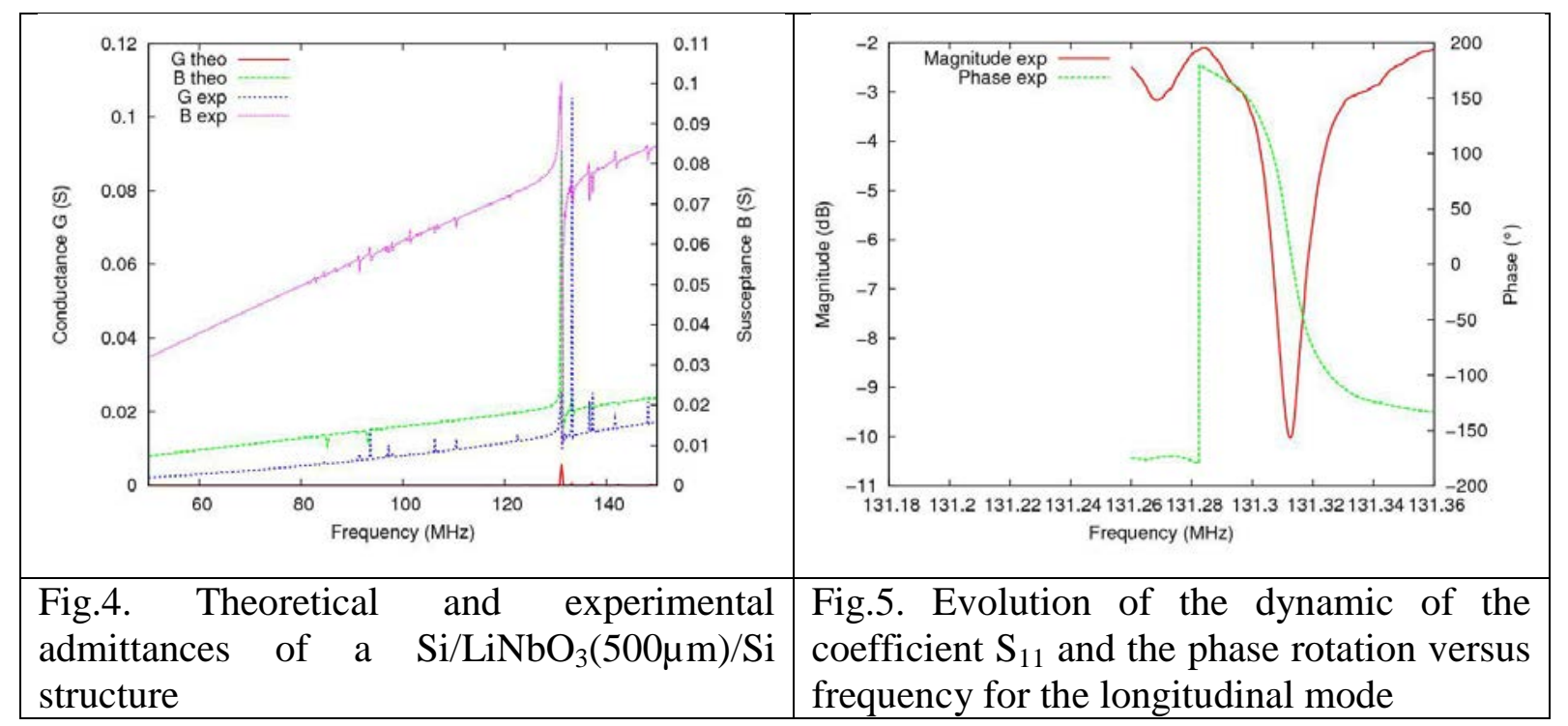

Theoretical and measured electrical admittances agree well and allow for identifying a main contribution corresponding to a guided longitudinal mode at $131 \mathrm{MHz}$ (fig.4). The

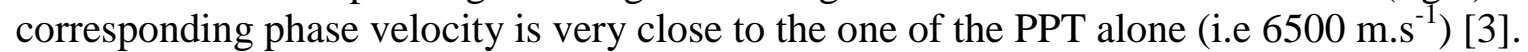

This resonator operating near $131 \mathrm{MHz}$ exhibits a quality factor of 13000 and an electromechanical coupling $\mathrm{ks}^{2}$ equal to $0.25 \%$ (twice higher than a SAW quartz resonator). The corresponding phase rotation $\left(320^{\circ}\right)$ and the dynamic of its electrical reflection coefficient $\mathrm{S}_{11}$ equal to -8dB reveal compatible with oscillator applications (fig.5).

A specific printed circuit has been implemented for the phase noise tests with our $\mathrm{Si} / 500 \mu \mathrm{m}$ PPT/Si resonator and the Colpitts oscillator (fig.6). The phase noise of the oscillator at $100 \mathrm{kHz}$ from the carrier shows a value less than $-160 \mathrm{dBc} / \mathrm{Hz}$ (fig.7), which can be honestly compared with other acoustic wave oscillators at such frequency, accounting for the fact that the device was excited with a quite low signal level $(-6 \mathrm{dBm})$. Therefore, increasing the excitation should allow for a significant reduction of the noise floor and then advantageously compete with standard solutions.

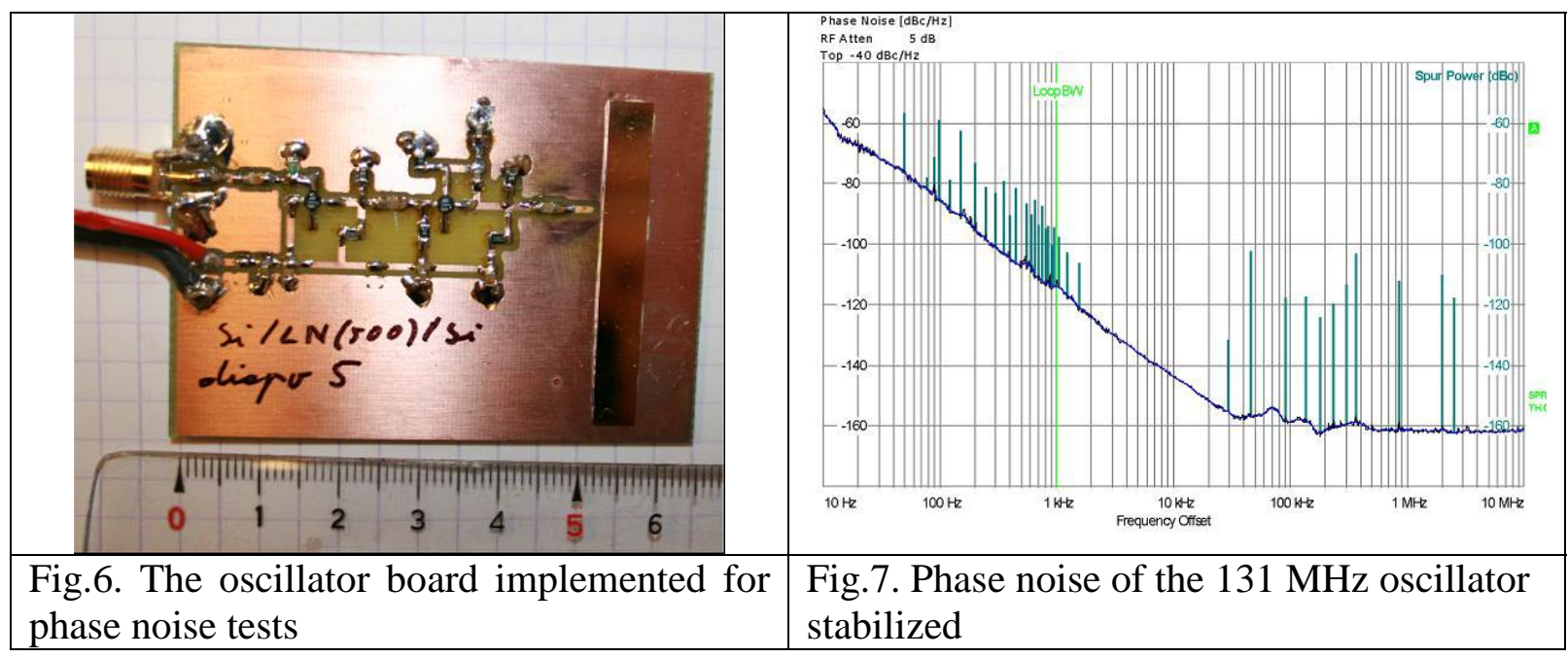


We have also studied the stability of this $131 \mathrm{MHz}$ oscillator, and we have obtained a frequency stability equal to $10^{-9}$ at less than 1s (fig.8). This experiment has been made at room temperature without any thermal compensation.

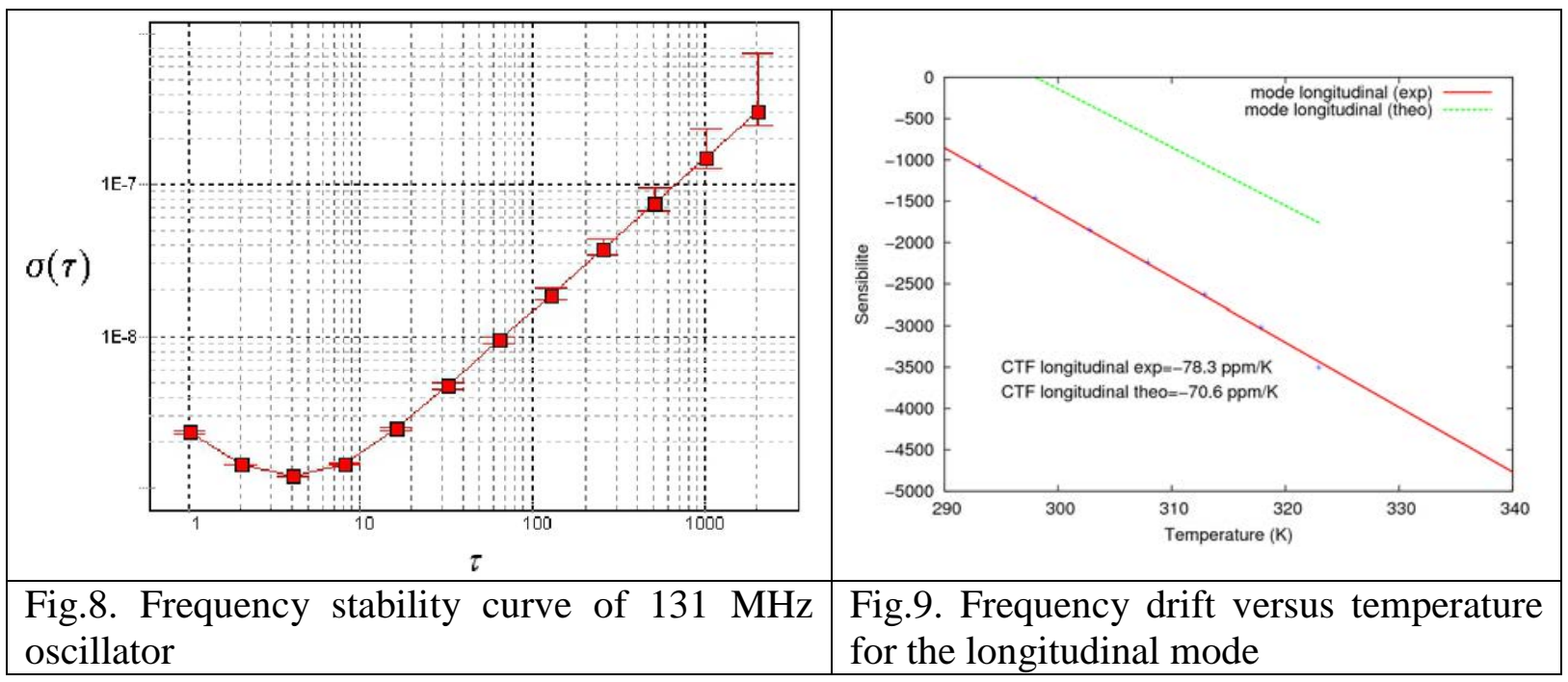

The frequency drift of this longitudinal mode at $131 \mathrm{MHz}$ versus the temperature is reported in fig.9. We have found frequency variations of $-78 \mathrm{ppm} / \mathrm{K}$ for the longitudinal mode for a thick $\mathrm{LiNbO}_{3}$ layer bonded between two Silicon layers. This value is sensibly the same than the one of isolated $\mathrm{LiNbO}_{3}$ devices. We can conclude that we obtain a significant thermal sensitivity for $\mathrm{Si} /$ thick $\mathrm{LiNbO}_{3}$ layer/Si and this value depends essentially of the material used for the PPT layer and cannot be reduced by the two guiding substrates. The further experiments consists in studying a Si/thinned PPT layer/Si in order to obtain a monomode acoustic wave device with an isolated mode with a low thermal sensitivity.

\section{Si/thinned PPT/Si- BASED WAVEGUIDES}

The study of the dispersion properties enables to define a specific configuration using a thinned PPT layer [4]. Interesting guidance properties have been obtained for a ratio between the thickness of the layer and the period of inverted domains lower than 1 and as a result the maximum of the electromechanical coupling is obtained for a $25-35 \mu \mathrm{m}$ thick $\mathrm{LiNbO}_{3} / \mathrm{LiTaO}_{3}$ layer for a $50 \mu \mathrm{m}$ period. The global flow-chart to fabricate Si/thinned PPT layer/Si acoustic waveguides is approximately the same than the process used for Si/thick PPT/Si (fig.2). The supplementary step consists in lapping and polishing the PPT layer in order to obtain a

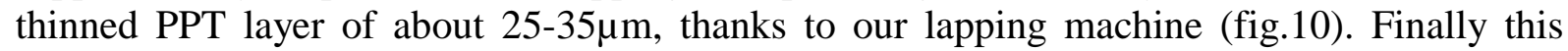
material stack is bonded on a second doped silicon wafer in order to define the aimed compact structure Si/PPT/Si. On figure 11, we can see a SEM observation obtained for a $25 \mu \mathrm{m}$ thick $\mathrm{LiNbO}_{3}$ layer confined between the two silicon substrates for a $50 \mu \mathrm{m}$ period. 


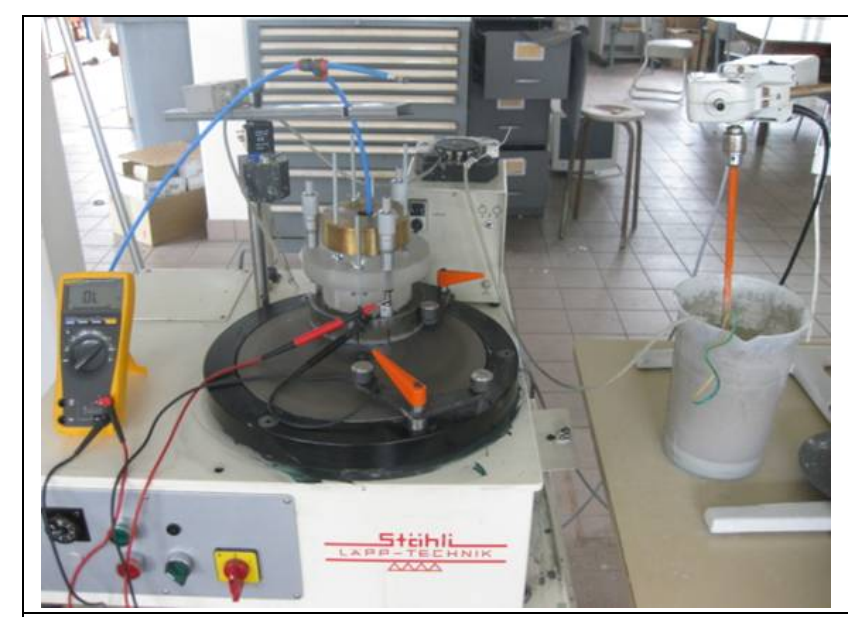

Fig.10. Photograph of the equipment used for lapping/polishing operations

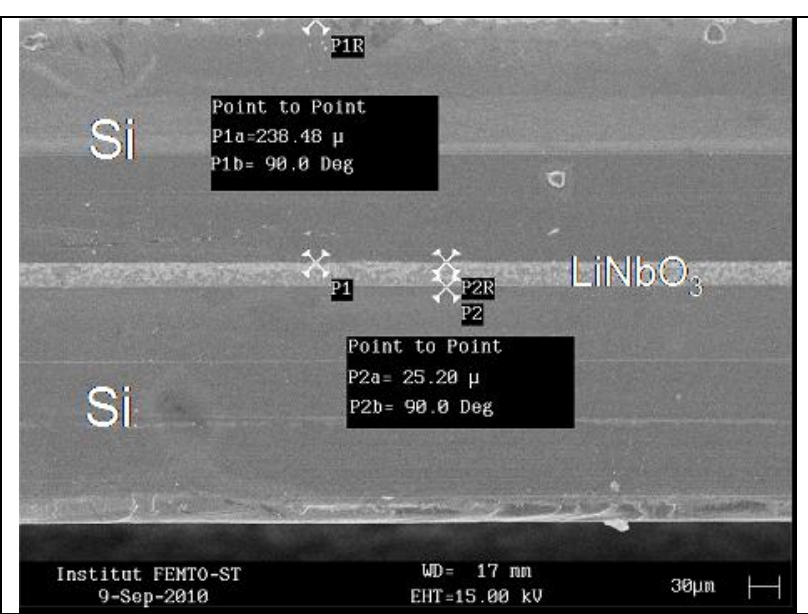

Fig.11. SEM view of a Si/thinned PPT/Si transducer

Operational test vehicles have been achieved using $\mathrm{LiNbO}_{3}$ and $\mathrm{LiTaO}_{3}$ wafers as poled ferroelectric layer. Experimental results of the Si/thinned PPT layer/Si devices with a $50 \mu \mathrm{m}$ period are reported in fig.12. For the two materials, only one contribution is obtained: at $110 \mathrm{MHz}$ for a $25 \mu \mathrm{m}$ thick $\mathrm{LiNbO}_{3}$ layer and at $88 \mathrm{MHz}$ for a $35 \mu \mathrm{m}$ thick $\mathrm{LiTaO}_{3}$ layer. Unfortunately, these monomode acoustic devices, due to a non homogenous thickness of the PPT layer along the several millimeter long ferroelectric gratings, don't exhibit properties compatible with oscillator applications.

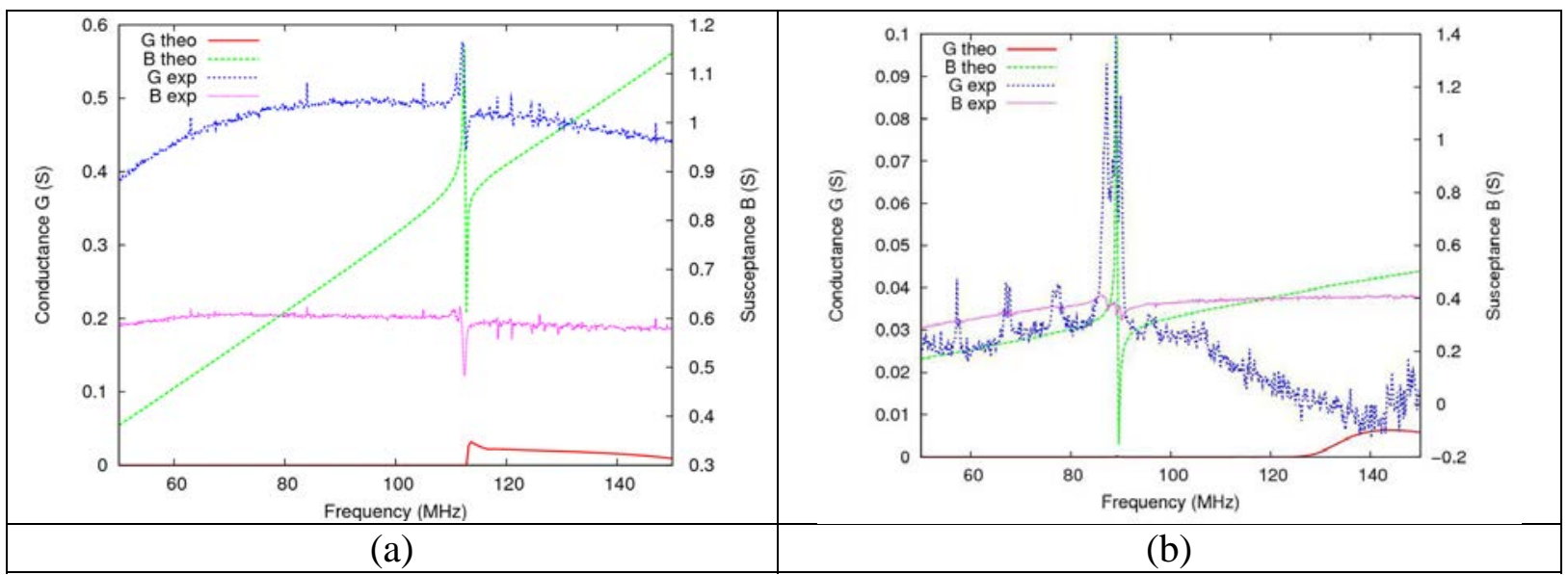

Fig.12. Theory/experitment assessment for a Si/thinned PPT/Si device with 50 $\mu \mathrm{m}$ of poling period built on a Z-cut $\mathrm{LiNbO}_{3}$ plate $(25 \mu \mathrm{m})$ (a) and a Z-cut $\mathrm{LiTaO}_{3}$ plate $(35 \mu \mathrm{m})$ (b)

We have also studied the frequency drift of the isolated mode versus the temperature for a $50 \mu \mathrm{m}$ period structure (fig.13). We have found frequency variations of $-33 \mathrm{ppm} / \mathrm{K}$ for the isolated mode for a $25 \mu \mathrm{m}$ thick $\mathrm{LiNbO}_{3}$ layer and of $-31 \mathrm{ppm} / \mathrm{K}$ for a $35 \mu \mathrm{m}$ thick $\mathrm{LiTaO}_{3}$ layer. So we can conclude that bonding onto two silicon wafers and lapping/polishing the $\mathrm{LiNbO}_{3}$ layer have compensated this frequency drift versus temperature by a factor 2 . Moreover the temperature coefficient of frequency (TCF) value of the compact structure is close to the TCF value of the silicon guiding substrate. So we can conclude that if we choose an appropriate insensitive material as guiding substrate, we can obtain an insensitive resonator versus temperature. 


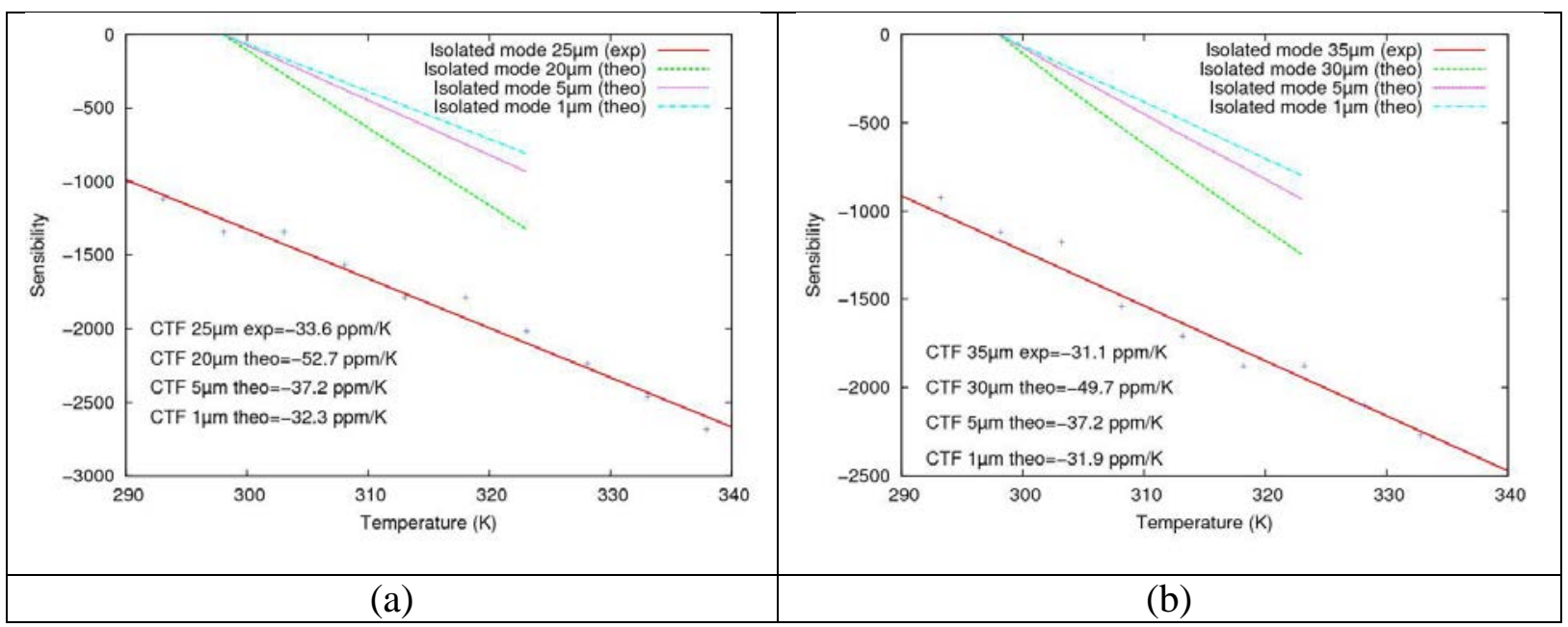

Fig.13. Frequency drift versus temperature for the isolated mode of a $50 \mu \mathrm{m}$ period devicetheory/experiment assessment on a Z-cut $\mathrm{LiNbO}_{3}$ plate $(25 \mu \mathrm{m})(\mathrm{a})$ and a $\mathrm{Z}$-cut $\mathrm{LiTaO}_{3}$ plate $(35 \mu \mathrm{m})(\mathrm{b})$

\section{CONCLUSION}

We have proposed a new acoustic resonator concept based on a periodically poled transducer in a piezoelectric substrate $\left(\mathrm{LiNbO}_{3}\right.$ or $\left.\mathrm{LiTaO}_{3}\right)$ embedded between two silicon guiding substrates in order to create an acoustic waveguide. A resonator operating at $131 \mathrm{MHz}$ have been successfully fabricated. This resonator presents the required properties to stabilize an oscillator at this frequency but however the developed resonator presents a significant thermal sensitivity (depending mainly on PPT substrate used). The following experiments have consisted in studying a Si/thinned PPT layer/Si: monomode acoustic wave devices with an isolated mode have been successfully fabricated with a low thermal sensitivity. A thermal insensitivity is possible with an appropriate choice of guiding susbtrate. However these monomode devices don't exhibit properties compatible with oscillator requirements due mainly to technological limits to be solved. Future works consist in improving the lapping process in order to obtain a homogeneous thickness for the compact structure, studying the possibility to reduce the noise floor of the oscillator with increasing the input power of the resonator at $131 \mathrm{MHz}$ and trying to invert micrometric periods in order to achieve a $2 \mathrm{GHz}$ frequency resonator.

\section{ACKNOWLEDGMENT}

This work is supported by the French DGA (Délégation Générale de l'Armement) under grant \#0734020.

\section{REFERENCES}

[1] E. Courjon et al, "Pure longitudinal plate mode excited by poled domains transducers on $\mathrm{LiNbO}_{3}$ ", Proc. of the IEEE IFCS, 2007

[2] E. Courjon et al, "Fabrication of periodically poled domains transducers on $\mathrm{LiNbO}_{3}$ ", Proc. of the IEEE IFCS, 2006

[3] E. Courjon et al, "Lamb wave transducers built on periodically poled Z-cut $\mathrm{LiNbO}_{3}$ wafers”, Journal of Applied Physics, 102, 114107, 2007

[4] E. Courjon et al, "An acoustic wave guide based on doubly-bonded silicon/PPT/silicon structures”, Proc. of the joint IEEE IFCS-EFTF, 2009 